\title{
A HPLC-UV Method for the Quantification of Regorafenib in Tumor
}

\author{
Yao Li", Meng-Ning Wei", Wen-Ji Zhang ${ }^{\#}$ and Zhi Shi \\ Department of Cell Biology \& Institute of Biomedicine, National Engineering Research Center of Genetic \\ Medicine, Guangdong Provincial Key Laboratory of Bioengineering Medicine, College of Life Science and \\ Technology, Jinan University, Guangzhou, Guangdong 510632, China
}

\begin{abstract}
Regorafenib has been approved for the treatment of colorectal cancer, gastrointestinal stromal tumor and hepatocellular carcinoma. High-performance liquid chromatography (HPLC) was developed and validated for determination of regorafenib in xenograft tumors. After protein precipitation with acetonitrile, regorafenib were separated using gradient elution (C18 Ultrabase column). Quantification was performed at $262 \mathrm{~nm}$. Calibration curves were linear over the range $48.8-50000 \mathrm{ng} / \mathrm{ml}$. The assay was applied to the determination of the drug in the tumor of nude mice receiving regorafenib $50 \mathrm{mg}$ orally, and could be useful for therapeutic drug monitoring of regorafenib in routine clinical practice.
\end{abstract}

Keywords: Regorafenib, HPLC-UV, tumor.

\section{INTRODUCTION}

Regorafenib (BAY 73-4506), an oral multikinase inhibitor of angiogenic, stromal and oncogenic receptor tyrosine kinases, approved by FDA in 2012 for the treatment of patients with metastatic colorectal cancer who have been previously treated with fluoropyrimidine-, oxaliplatin- and irinotecan-based chemotherapy, an anti-VEGF therapy, and, if RAS wildtype, an anti-EGFR therapy [1, 2]. The FDA approved use of regorafenib was extended to treatment of patients with locally advanced, unresectable or metastatic gastrointestinal stromal tumor who have been previously treated with imatinib mesylate and sunitinib malate in 2013 [3] and to treatment of patients with hepatocellular carcinoma who have been previously treated with sorafenib in 2017 [4]. Regorafenib has exhibited cytostatic or cytotoxic activity in various cell lines and xenografts [5-8] and has demonstrated its activity in early phase clinical trials in adults with cancer $[9,10]$. We recently reported that regorafenib could antagonize ABCB1 or ABCG2mediated multidrug resistance, and enhance the antitumor activity of lapatinib in preclinical models of human colorectal cancer [11-13]. In clinic, the most common regorafenib-associated adverse events include hand-foot skin reaction, rash or desquamation, hypertension, stomatitis, liver abnormalities, diarrhea, fatigue and so on [14-17]. Therefore, appropriate monitoring, and management are essential to decrease the incidence, severity and duration of regorafenibassociated adverse events.

*Address correspondence to this author at the Room 708, The $2^{\text {nd }}$ Engineer and Scientific Building, 601 Huangpu Road West, Guangzhou, Guangdong 510632, China; Tel: +86-20-852-245-25; Fax: +86-20-852-259-77;

E-mail: tshizhi@jnu.edu.cn

"The first three authors contribute equally to this work.

ISSN: 1929-2260 / E-ISSN: 1929-2279/20
In this study, we report a validated method that allows for the sensitive determination of regorafenib in xenograft tumor. The method exhibited excellent performance in terms of high selectivity, wide linear range $(48.8-50000 \mathrm{ng} / \mathrm{ml})$ and simpleness and costefficient. The method was successfully applied to study the pharmacokinetics of regorafenib in tumor.

\section{MATERIAL AND METHODS}

\subsection{Reagents and Materials}

Regorafenib (A8236) from APExBIO Technology were dissolved in acetonitrile and stored at $-20{ }^{\circ} \mathrm{C}$. HPLC grade acetonitrile (75-05-8), trifluoroacetic acid (76-05-8) and C18 Ultrabase column (Athena C18, 5 $\mu \mathrm{m}, 120 \AA)$ (8.462571.0001) used were from ANPEL, Shanghai. The operate system was performed using Waters e2695 series HPLC with Waters 2998 Photodiode Array Detector. All data were acquired employing Empower 3 Quantitative Analysis version analyst data processing software. Balb/c nude mice were obtained from the Guangdong Medical Laboratory Animal Center and maintained with sterilized food and water.

\subsection{Sample Preparation}

The stock solutions of regorafenib $(300 \mu \mathrm{g} / \mathrm{ml})$ prepared in acetonitrile. Standard solutions of regorafenib at concentrations of $48.8 \mathrm{ng} / \mathrm{ml}, 195 \mathrm{ng} / \mathrm{ml}$, $781 \mathrm{ng} / \mathrm{ml}, 3125 \mathrm{ng} / \mathrm{ml}, 12500 \mathrm{ng} / \mathrm{ml}$ and $50000 \mathrm{ng} / \mathrm{ml}$ prepared by serial dilution of regorafenib stock solution with acetonitrile. All standard solutions were kept at -20 ${ }^{\circ} \mathrm{C}$. A pharmacokinetic mouse study was conducted with the purpose of showing the applicability of the assay because human samples were not yet available. Fourteen female nude mice with 5 weeks old and 14-17

(C) 2020 Neoplasia Research 
g weight were used. Every mouse was injected subcutaneously of the human colonrectal cancer HCT116 cells $\left(3 \times 10^{6}\right.$ in $100 \mu$ l of DMEM) under the right shoulder. When the subcutaneous tumors were approximately $0.5 \times 0.5 \mathrm{~cm}^{2}$ (two perpendicular diameters) in size, the mice were randomized into two groups and treated with the following regimens: vehicle alone $\quad(0.5 \%$ hydroxypropyl-methylcellulose, $\quad 0.1 \%$ Tween 80/PBS; $100 \mu \mathrm{L}$ ) and regorafenib $(50 \mathrm{mg} / \mathrm{kg}$, orally) daily for 21 days. In the 21st day, four hours after the last treatment, the xenograft tumor were taking out and a small piece of tumor tissue were chopped and lysated by RIPA buffer. The lysis was quantitated to $10 \mathrm{mg} / \mathrm{ml}$ and proteins included were precipitated with two times acetonitrile and the supernatant after high-speed centrifugation was collected into injection tubes. The supernatant could be concentrated under nitrogen if the content is too low. The test for recovery was carried out by adding 100 $\mu \mathrm{g} / \mathrm{ml}$ standard drugs to $50 \mu \mathrm{l}$ blank tumor lysis and then treated in the same way as samples.

\subsection{HPLC Conditions}

The mobile phases were as follows: mobile phase solvent $A$ was methanol ( $0.1 \%$ TFA in acetonitrile $\mathrm{v} / \mathrm{v})$ and mobile phase solvent $B$ was distilled water $(0.1 \%$ TFA in water $\mathrm{v} / \mathrm{v}$ ). The initial mobile phase composition of $10 \%$ solvent $A$ and $90 \%$ solvent $B$ was maintained for $5 \mathrm{~min}$. Between 5 and $10 \mathrm{~min}$, the percentage of solvent $A$ was changed to $95 \%$. Between 15 and 20 min, the percentage of solvent $A$ was then returned to
$10 \%$. The overall run time was $20 \mathrm{~min}$. The flow rate was $1 \mathrm{ml} / \mathrm{min}$ and the injection volume was 20-50 $\mu \mathrm{l}$.

\section{RESULTS}

\subsection{Chromatography and Linearity}

Representative chromatograms of standard drug are shown in Figure 1. Regorafenib was eluted with a gradient with solvent $A(0.1 \%$ TFA in acetonitrile $)$ and solvent $B(0.1 \%$ TFA in water) at the wavelength of 262 $\mathrm{nm}$ and the peak occurs at $12.2 \mathrm{~min}$ (Figure 1A). The linearity of the method was evaluated over a concentration range of $48-50,000 \mathrm{ng} / \mathrm{ml}$. After log process, the stand curve of regorafenib is $y=0.927 x+$ $5.216\left(R^{2}=0.999\right)$ (Figure $1 B$ and $\left.1 C\right)$. The assay showed good correlation coefficients $(r 2>0.99)$.

\subsection{Recovery}

Recovery tests were performed to evaluate the accuracy of the method. The extraction recoveries for regorafenib at the reduplicative concentration levels were $97.0-98.3 \%$. The benefit chromatogram was showed in Figure 2. Higher recovery values with $97.66 \pm 0.91 \%$ were achieved, which indicates that the method is efficient and rapid.

\subsection{Analysis of Samples}

The control blank tumor lysis (Figure $3 \mathbf{A}$ ) has no other peaks at the same time of $12.2 \mathrm{~min}$. No significant interference was observed in the

A
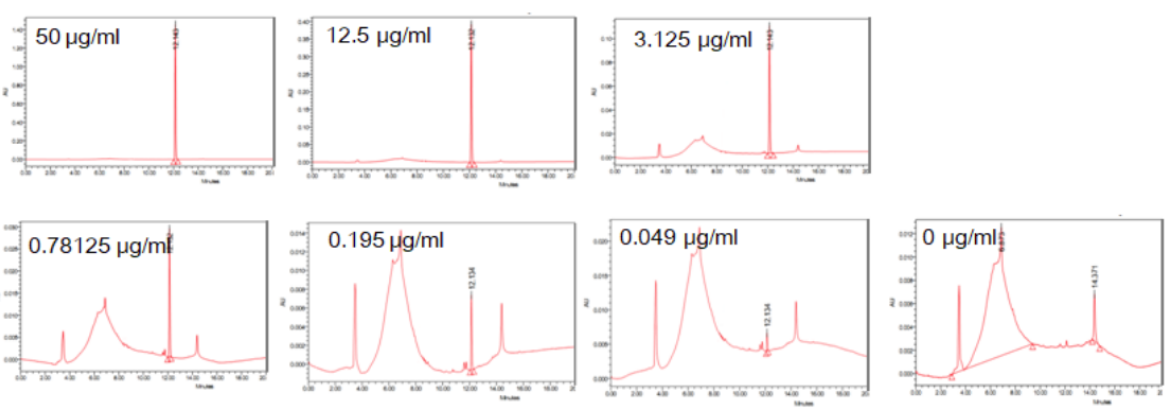

B

\begin{tabular}{ll}
\hline X-axis-ng/mL & Y-axis-Area \\
\hline 50000 & 6311388 \\
12500 & 1724120 \\
3125 & 474108 \\
781.25 & 125832 \\
195.313 & 34908 \\
48.828 & 10496
\end{tabular}

C

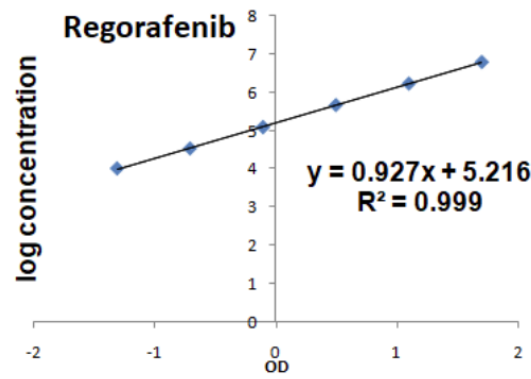

Figure 1: The representative chromatograms $(\mathbf{A})$, area of peaks $(\mathbf{B})$ and standard curve $(\mathbf{C})$ of regorafenib are shown. 


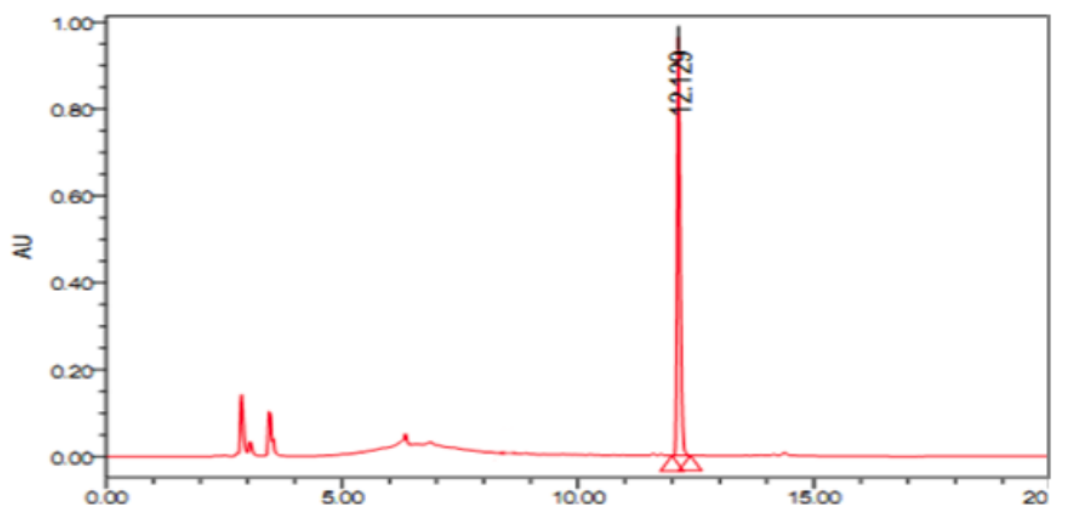

Figure 2: The representative chromatogram of regorafenib recovery test is shown.

A

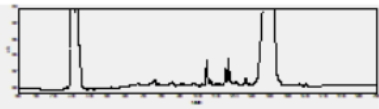

C

\begin{tabular}{cc}
\hline Code & Con.(ng/mL) \\
\hline 1 & 727 \\
2 & 608 \\
3 & 547 \\
4 & 435 \\
5 & 363 \\
6 & 404 \\
7 & 467 \\
8 & 471 \\
9 & 942 \\
10 & 661 \\
11 & 536 \\
12 & 425 \\
13 & 680 \\
14 & 1107 \\
\hline
\end{tabular}

B

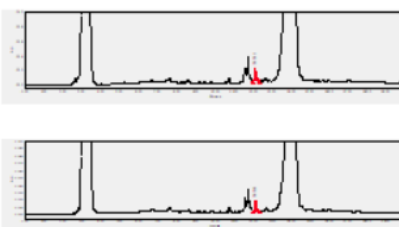

$\# 1$

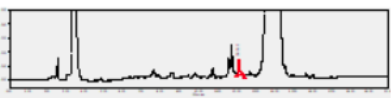

\#8

$\# 2$

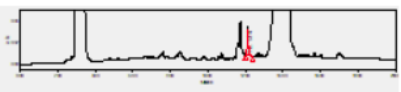

\#9

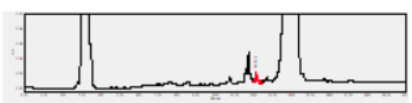

$\# 3$

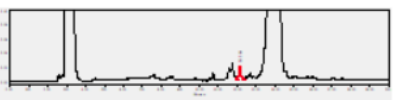

\#10

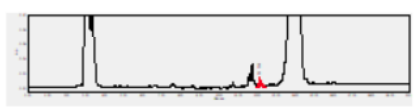

$\# 4$

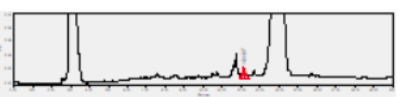

\#11

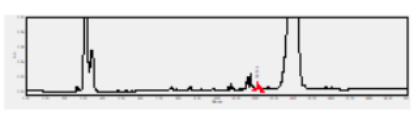

\#5

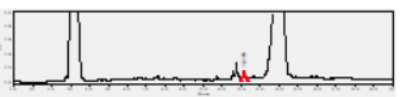

$\# 12$

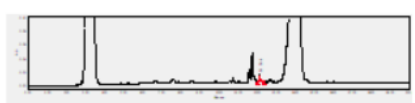

\#6

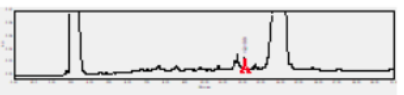

$\# 13$

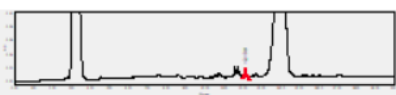

$\# 7$

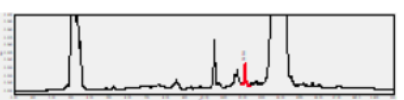

Figure 3: The chromatograms in control group (A), 14 tumor samples (B) and concentrations (C) of regorafenib are shown.

chromatograms of control tumor lysis without regorafenib treatment. Tumor regorafenib concentrations were analyzed in 14 nude mice under regorafenib monotherapy. The concentration profile of regorafenib is $598 \pm 213 \mathrm{ng} / \mathrm{ml}$, indicating that all concentrations were in the range of $48-50,000 \mathrm{ng} / \mathrm{ml}$. The concentrations of regorafenib in tumor are demonstrated in Figure 3B and the peaks were shown in Figure 3C. Taken together, these results show that the present analytical method can be used for quantification of regorafenib in tumors.

\section{DISCUSSION}

Quantitative determination of regorafenib in human plasma has been reported with high-performance liquid chromatography and ultraviolet detection, and coefficients and accuracies of variation for intra- and inter-day assays were $<12.2 \%$ and $<9.4 \%$ respectively for regorafenib over a linear range from 10 to $10,000 \mathrm{ng} / \mathrm{mL}$ [18]. There are two additional reported methods for analysis of regorafenib, stable-isotope dilution liquid chromatography-tandem mass spectrometry [19] and bioanalytical liquid chromatography-tandem mass spectrometric assay [20] in human plasma. Here, we established an easy and reproducible method for determination of regorafenib concentration in tumor. This assay facilitates a precious determination of regorafenib at least in the broad range of $48-50,000 \mathrm{ng} / \mathrm{ml}$. No interference with other compounds was detected. Termovap sample concentrator is a good choice if the 
drug content is beyond the lower limit of detection. It is noteworthy that the sample had better not be blown dry and then high-speed centrifugation is necessary. In the present work, runtime for 20 min linear gradient including equilibration step between two runs is a little long of this technique in the context of regorafenib in routine practice.

In conclusion, a sensitive and rapid HPLC-UV method was developed for the quantification of regorafenib in tumor, and the concentration of regorafenib in tumor were detected. This simple and cost-effective method can also be used for pharmacokinetic and pharmacodynamics studies of regorafenib and may contribute to the spreading of regorafenib monitoring in hospital laboratories not having LC/MS/MS.

\section{ACKNOWLEDGEMENTS}

This work was supported by funds from the Science and Technology Program of Guangzhou No. 201704030058.

\section{CONFLICTS OF INTEREST}

There is no conflict of interest.

\section{REFERENCES}

[1] Wilhelm SM, Dumas J, Adnane L, Lynch M, Carter CA, Schutz G, Thierauch KH and Zopf D. Regorafenib (BAY 734506): a new oral multikinase inhibitor of angiogenic, stromal and oncogenic receptor tyrosine kinases with potent preclinical antitumor activity. International journal of cancer Journal international du cancer 2011; 129(1): 245-255. https://doi.org/10.1002/ijc.25864

[2] FDA approves regorafenib (Stivarga) for metastatic colorectal cancer. Oncology 2012; 26(10): 896.

[3] FDA approves regorafenib (Stivarga) for GIST. Oncology 2013; 27(3): 164.

[4] Duffy AG and Greten TF. Liver cancer: Regorafenib as second-line therapy in hepatocellular carcinoma. Nat Rev Gastroenterol Hepatol 2017; 14(3): 141-142. https://doi.org/10.1038/nrgastro.2017.7

[5] Daudigeos-Dubus E, Le Dret L, Lanvers-Kaminsky C, Bawa O, Opolon P, Vievard A, Villa I, Pages M, Bosq J, Vassal G, Zopf D and Geoerger B. Regorafenib: Antitumor Activity upon Mono and Combination Therapy in Preclinical Pediatric Malignancy Models. PloS one 2015; 10(11): e0142612. https://doi.org/10.1371/journal.pone.0142612

[6] D'Alessandro R, Refolo MG, Lippolis C, Giannuzzi G, Carella $\mathrm{N}$, Messa C, Cavallini A and Carr BI. Antagonism of sorafenib and regorafenib actions by platelet factors in hepatocellular carcinoma cell lines. BMC cancer 2014; 14: 351.

https://doi.org/10.1186/1471-2407-14-351

[7] Hamed HA, Tavallai S, Grant S, Poklepovic A and Dent P. Sorafenib/regorafenib and lapatinib interact to kill CNS tumor cells. Journal of cellular physiology 2015; 230(1): 131-139. https://doi.org/10.1002/jcp.24689
Schmieder R, Hoffmann J, Becker M, Bhargava A, Muller T, Kahmann N, Ellinghaus $P$, Adams R, Rosenthal A, Thierauch $\mathrm{KH}$, Scholz A, Wilhelm SM and Zopf D. Regorafenib (BAY 73-4506): antitumor and antimetastatic activities in preclinical models of colorectal cancer. International journal of cancer Journal international du cancer 2014; 135(6): 1487-1496. https://doi.org/10.1002/ijc.28669

[9] Davis SL, Eckhardt SG, Messersmith WA and Jimeno A. The development of regorafenib and its current and potential future role in cancer therapy. Drugs of today 2013; 49(2): 105-115. https://doi.org/10.1358/dot.2013.49.2.1930525

[10] George S, Wang Q, Heinrich MC, Corless CL, Zhu M, Butrynski JE, Morgan JA, Wagner AJ, Choy E, Tap WD, Yap JT, Van den Abbeele AD, Manola JB, Solomon SM, Fletcher $\mathrm{JA}$, von Mehren $\mathrm{M}$, et al. Efficacy and safety of regorafenib in patients with metastatic and/or unresectable GI stromal tumor after failure of imatinib and sunitinib: a multicenter phase II trial. Journal of clinical oncology : official journal of the American Society of Clinical Oncology 2012; 30(19): 2401-2407.

https://doi.org/10.1200/JCO.2011.39.9394

[11] Zhang YK, Wang YJ, Lei ZN, Zhang GN, Zhang XY, Wang DS, Al-Rihani SB, Shukla S, Ambudkar SV, Kaddoumi A, Shi $Z$ and Chen ZS. Regorafenib antagonizes BCRP-mediated multidrug resistance in colon cancer. Cancer Lett 2019; 442: 104-112. https://doi.org/10.1016/j.canlet.2018.10.032

[12] Wang YJ, Zhang YK, Zhang GN, Al Rihani SB, Wei MN, Gupta P, Zhang XY, Shukla S, Ambudkar SV, Kaddoumi A, Shi $Z$ and Chen ZS. Regorafenib overcomes chemotherapeutic multidrug resistance mediated by ABCB1 transporter in colorectal cancer: In vitro and in vivo study. Cancer Lett 2017; 396: 145-154.

https://doi.org/10.1016/j.canlet.2017.03.011

[13] Zhang WJ, Li Y, Wei MN, Chen Y, Qiu JG, Jiang QW, Yang $Y$, Zheng DW, Qin WM, Huang JR, Wang K, Wang YJ, Yang $\mathrm{DH}$, Chen ZS and Shi Z. Synergistic antitumor activity of regorafenib and lapatinib in preclinical models of human colorectal cancer. Cancer Lett 2017; 386: 100-109. https://doi.org/10.1016/j.canlet.2016.11.011

[14] Xie G, Gong Y, Wu S, Li C, Yu S, Wang Z, Chen J, Zhao Q, $\mathrm{Li} \mathrm{J}$ and Liang $\mathrm{H}$. Meta-Analysis of Regorafenib-Associated Adverse Events and Their Management in Colorectal and Gastrointestinal Stromal Cancers. Adv Ther 2019; 36(8): 1986-1998. https://doi.org/10.1007/s12325-019-01013-5

[15] Yin X, Yin Y, Shen C, Chen H, Wang J, Cai Z, Chen Z and Zhang B. Adverse events risk associated with regorafenib in the treatment of advanced solid tumors: meta-analysis of randomized controlled trials. Onco Targets Ther 2018; 11: 6405-6414.

https://doi.org/10.2147/OTT.S156760

[16] Cao M, Li F, Wang Y and Zhang J. Treatment-related serious adverse events and fatal adverse events with regorafenib in cancer patients: a meta-analysis of phase 3 randomized controlled trials. Invest New Drugs 2017; 35(6): 834-838. https://doi.org/10.1007/s10637-017-0512-6

[17] De Wit M, Boers-Doets CB, Saettini A, Vermeersch K, de Juan CR, Ouwerkerk J, Raynard SS, Bazin A and Cremolini C. Prevention and management of adverse events related to regorafenib. Support Care Cancer 2014; 22(3): 837-846. https://doi.org/10.1007/s00520-013-2085-z

[18] Fujita K, Miura M and Shibata H. Quantitative determination of regorafenib and its two major metabolites in human plasma with high-performance liquid chromatography and ultraviolet detection. Biomed Chromatogr 2016; 30(10): 16111617.

https://doi.org/10.1002/bmc.3730 
[19] Hafner FT, Werner D and Kaiser M. Determination of regorafenib (BAY 73-4506) and its major human metabolites BAY 75-7495 (M-2) and BAY 81-8752 (M-5) in human plasma by stable-isotope dilution liquid chromatographytandem mass spectrometry. Bioanalysis 2014; 6(14): 19231937.

https://doi.org/10.4155/bio.14.52
[20] Luethi D, Durmus S, Schinkel AH, Schellens JH, Beijnen JH and Sparidans RW. Liquid chromatography-tandem mass spectrometric assay for the multikinase inhibitor regorafenib in plasma. Biomedical chromatography : BMC 2014; 28(10): 1366-1370.

https://doi.org/10.1002/bmc.3176

Received on 05-03-2020

Accepted on 09-05-2020

Published on 12-05-2020

DOI: https://doi.org/10.30683/1929-2279.2020.09.01

(C) 2020 Li et al.; Licensee Neoplasia Research.

This is an open access article licensed under the terms of the Creative Commons Attribution Non-Commercial License (http://creativecommons.org/licenses/by-nc/3.0/) which permits unrestricted, non-commercial use, distribution and reproduction in any medium, provided the work is properly cited. 